ISSN 2304-6740

www.mdpi.com/journal/inorganics

Article

\title{
Bottom-Up, Wet Chemical Technique for the Continuous Synthesis of Inorganic Nanoparticles
}

\section{Annika Betke and Guido Kickelbick*}

Inorganic Chemistry, Saarland University, Am Markt Zeile 3, 66125 Saarbrücken, Germany; E-Mail: annika.betke@uni-saarland.de

* Author to whom correspondence should be addressed; E-Mail: guido.kickelbick@uni-saarland.de; Tel.: +49-0-681-302 (ext. 70651); Fax: +49-0-681-302 (ext. 70652).

Received: 20 December 2013; in revised form: 14 January 2014 / Accepted: 16 January 2014 / Published: 27 January 2014

\begin{abstract}
Continuous wet chemical approaches for the production of inorganic nanoparticles are important for large scale production of nanoparticles. Here we describe a bottom-up, wet chemical method applying a microjet reactor. This technique allows the separation between nucleation and growth in a continuous reactor environment. Zinc oxide $(\mathrm{ZnO})$, magnetite $\left(\mathrm{Fe}_{3} \mathrm{O}_{4}\right)$, as well as brushite $\left(\mathrm{CaHPO}_{4} \cdot 2 \mathrm{H}_{2} \mathrm{O}\right)$, particles with a small particle size distribution can be obtained continuously by using the rapid mixing of two precursor solutions and the fast removal of the nuclei from the reaction environment. The final particles were characterized by FT-IR, TGA, DLS, XRD and SEM techniques. Systematic studies on the influence of the different process parameters, such as flow rate and process temperature, show that the particle size can be influenced. Zinc oxide was obtained with particle sizes between $44 \mathrm{~nm}$ and $102 \mathrm{~nm}$. The obtained magnetite particles have particle sizes in the range of $46 \mathrm{~nm}$ to $132 \mathrm{~nm}$. Brushite behaves differently; the obtained particles were shaped like small plates with edge lengths between $100 \mathrm{~nm}$ and $500 \mathrm{~nm}$.
\end{abstract}

Keywords: continuous synthesis; precipitation; inorganic nanoparticles; microjet reactor

\section{Introduction}

Nanoparticles have been identified as major compounds for many applications in the last decades. They are used in many different fields such as medicine, optics, electronics or catalysis [1]. For this reason, there is a lot of interest in facile synthetic routes for nanoparticles with controllable size and 
narrow size distribution. There are many different possibilities for the production of particles but due to its simplicity, low cost, and easy application in industrial production, stirred tank batch reactor processes are still the most employed wet chemical systems [2,3]. However, this method has often limitations for the preparation of nanoparticles on an industrial scale, because of long mixing times and thus uncontrolled nucleation and growth. To obtain nanoparticles with particle sizes smaller than $100 \mathrm{~nm}$ very short mixing times are required. Although there are methods which can be employed on a laboratory scale to obtain rapid mixing, their scale up is quite difficult [4,5]. In addition, it would be of great benefit if the synthesis could be performed continuously, because this would eliminate differences in nanoparticle properties from batch to batch [6-8]. There are continuous techniques, such as mixing starting material solutions on a macroscopic scale (e.g., tee shaped connectors) or microreactors [9]. These techniques have been used already for the synthesis of anatase- $\mathrm{TiO}_{2}$, gold, and cobalt nanoparticles as well as tricalcium phosphate ceramics [10-13]. In general, all the abovementioned techniques require an improvement with respect to the mixing time. There are several studies, which indicate that the effect of mixing has an important influence on the particle size distribution. Experimental, as well as theoretical, precipitation experiments using a tee-mixer and barium sulfate as exemplary material show that the particles becomes smaller with increasing mixing intensity $[14,15]$. In further studies, it was found that confined impinging jet reactors are more efficient than tee-mixers. Using such a reactor type, it is possible to generate polymer nanoparticles which have potential application in biomedicine; for example for controlled drug delivery $[16,17]$. Biocompatible nanomaterial for biomedicine and pharmaceutical applications can also be produced by using a novel continuous industrial reactor, called NETmix. This reactor is a network of interconnected chambers and channels creating zones of complete mixing and segregation. This technique is used already for the synthesis of hydroxyapatite nanoparticles with extremely high purity and crystallinity [18]. Fast mixing is also fulfilled when a microjet reactor (Figure 1) is used. The excellent improvement is that the reagent solutions are forced with high pressure through a narrow cone in a reaction chamber that is constantly flushed with a gas flow. As a result, the obtained product is removed directly from the reaction chamber so that clogging is avoided.

Figure 1. Schematic set-up of the microjet reactor.

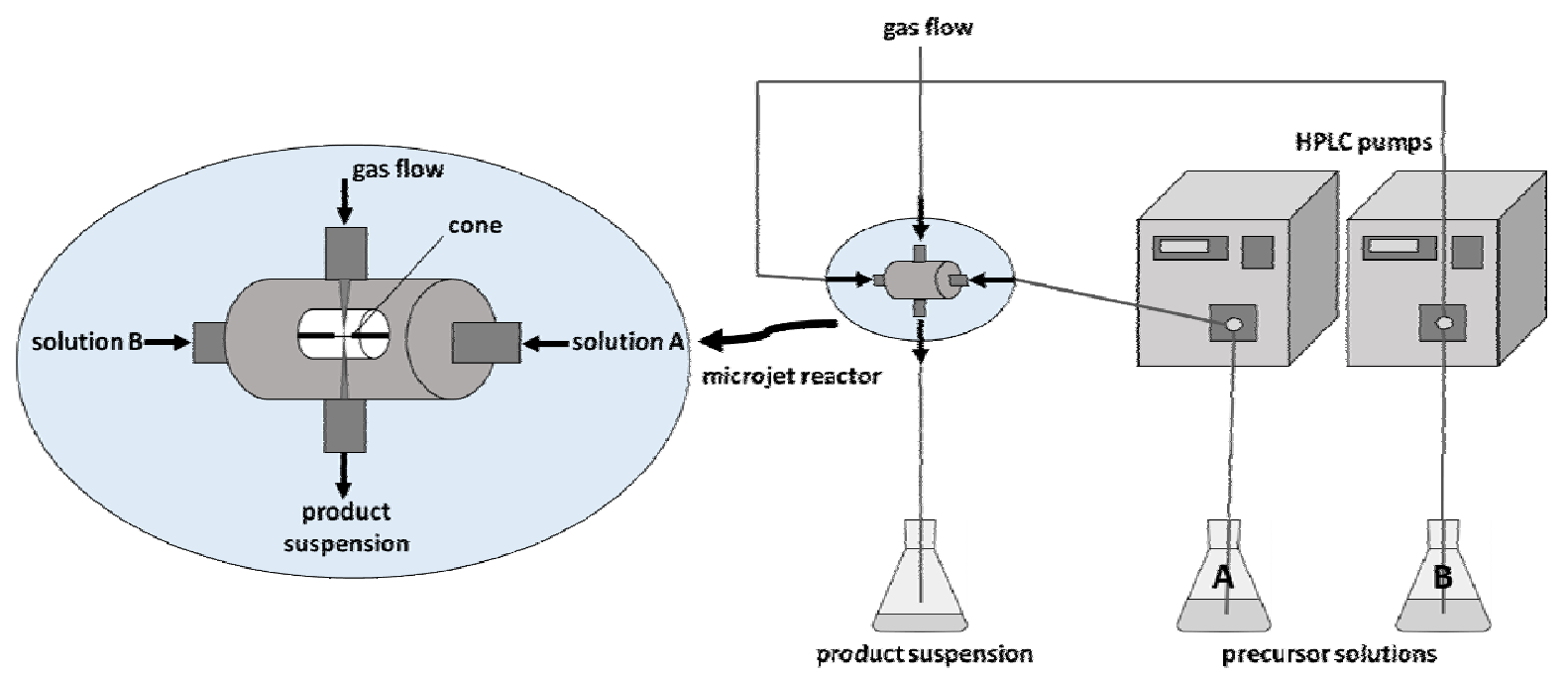


This technique can be used to perform different precipitation reactions continuously. Two pumps are used to transport the solutions containing the starting materials as dissolved substances to the microjet reactor. The collision takes place in a confined reaction environment, which is given by the format of the microjet reactor. Due to the fluid dynamics in the microjet reactor, there is a very short mixing time. Consequently, there is a maximum number of nuclei in an absolute homogeneous environment. In addition the nucleation rate is increased compared to the nucleus growth $[19,20]$. Directly after the nuclei are formed, they are transported from the reaction room to a tubing where the particle growth occurs. The length of this tubing up to the collection vessel influences the particle growth. The method has the advantage of being able to prepare nanoparticles even from a system with very low solubility products, e.g. barium sulfate [21]. However, it is also able to produce metal oxides, such as titania [22]. One great advantage is that the particles are obtained in a suspension, which could be used for a direct application, e.g. in spray coating or inkjet printing.

In this study, we investigated the microjet reactor technique for the synthesis of three types of inorganic nanoparticles, i.e., zinc oxide $(\mathrm{ZnO})$, magnetite $\left(\mathrm{Fe}_{3} \mathrm{O}_{4}\right)$, and brushite $\left(\mathrm{CaHPO}_{4} \cdot 2 \mathrm{H}_{2} \mathrm{O}\right)$. These particles are not only interesting for academic reasons, but also have applications in optoelectronics and clinical, as well as biomedical devices [23-25]. The goal was to define the possibilities and limitations of this technique with regard to the different process parameters, such as flow rate and temperature, on the result of the precipitation reaction. Here, we do not focus on the importance of the time between nuclei formation and collection of the products, which also influences the size of the particles as this will be investigated in a further study.

\section{Results and Discussion}

The synthesis of inorganic nanoparticles was carried out using a microjet reactor system. In order to reveal the wide application field of the microjet reactor we performed the synthesis of three different species: zinc oxide $(\mathrm{ZnO})$, magnetite $\left(\mathrm{Fe}_{3} \mathrm{O}_{4}\right)$, as well as brushite $\left(\mathrm{CaHPO}_{4} \cdot 2 \mathrm{H}_{2} \mathrm{O}\right)$. All of these three systems show a low solubility under the applied reaction conditions. Two isocratic preparative HPLC pumps were used to transport the solutions containing the starting materials as dissolved substances. In the microjet-reactor, these two solutions clash and the precipitation reaction takes place. The precipitate was directly removed from the reactor by the use of a nitrogen gas flow. This process was performed with various flow rates of the precursor solutions $(150 \mathrm{~mL} / \mathrm{min}$, $200 \mathrm{~mL} / \mathrm{min}$ and $250 \mathrm{~mL} / \mathrm{min})$ and at different temperatures $\left(25{ }^{\circ} \mathrm{C}, 50{ }^{\circ} \mathrm{C}\right.$ and $\left.75{ }^{\circ} \mathrm{C}\right)$. The reproducibility of the method was investigated by performing all experiments several times. The obtained material was thoroughly washed with water and the resulting compound was characterized applying FT-IR-spectroscopy, XRD, TGA and DLS analysis, as well as SEM. The final products were analyzed with respect to changes in the composition, the particle size and morphology depending on the process parameters.

\subsection{Zinc Oxide}

The synthesis of zinc oxide was performed by using aqueous solutions of zinc chloride and sodium hydroxide as starting materials (Equation 1) for the solution A and B, respectively. 


$$
\mathrm{ZnCl}_{2}+2 \mathrm{NaOH} \rightarrow \mathrm{ZnO}+2 \mathrm{NaCl}+\mathrm{H}_{2} \mathrm{O} .
$$

Under conventional precipitation conditions in an open vessel, the same starting materials deliver disc-like $\mathrm{ZnO}$ submicrometer structures with diameters between $300 \mathrm{~nm}$ and $500 \mathrm{~nm}$ [26].

Smaller particles could be obtained applying controlled double-jet-precipitation, which produces primary particles with diameters between $20-30 \mathrm{~nm}$ that tend to agglomerate in ellipsoidal particles with sizes of a few hundred nanometers [5].

The particles that were obtained by using the microjet reactor were characterized using various techniques. FT-IR-analysis of the prepared materials showed no specific signals with exception of $\mathrm{OH}$ and $\mathrm{CO}$ bands of adsorbed $\mathrm{CO}_{2}$ and $\mathrm{H}_{2} \mathrm{O}$ as well as a strong $\mathrm{ZnO}$ band around $400 \mathrm{~cm}^{-1}$.

Thermogravimetric analysis (Figure 2) was performed to determine the amount of adsorbed $\mathrm{CO}_{2}$ and $\mathrm{H}_{2} \mathrm{O}$. The results show that the samples contain between $5 \%$ and $6 \%$ adsorbed species. The development of the mass loss looks similar for all samples.

Figure 2. Thermogravimetric analysis of the final products. The samples show a mass loss of between 5 and $6 \%$.

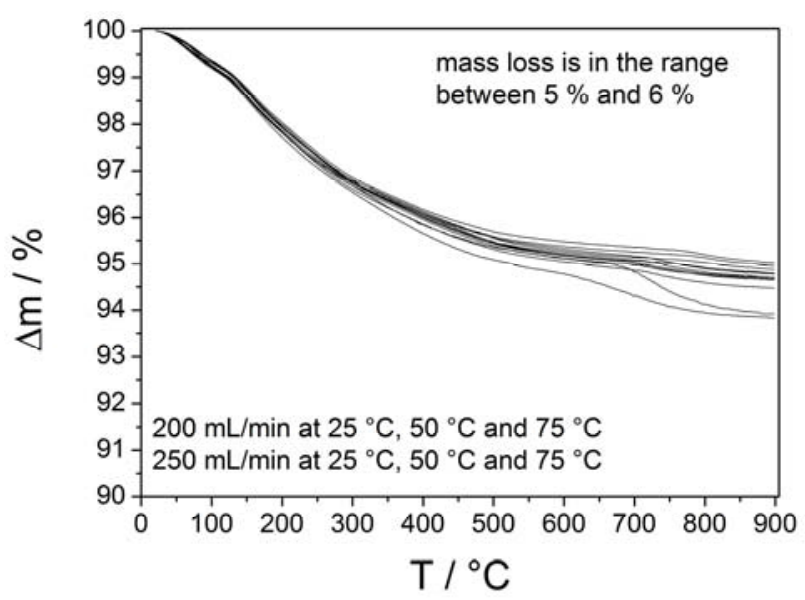

X-ray powder diffraction was applied to study the phase composition and crystallite size of the obtained material in dependence on the different synthesis parameters. The XRD pattern show that in each case pure zinc oxide is generated (Figure 3). The crystallite sizes decrease with increasing temperature and increasing flow rate (Table 1).

A further important parameter is the particle size including the size distribution, which is given by the standard deviation of the particle size. These parameters were determined using dynamic light scattering (Figure 4). The samples were dispersed in ethanol by the exposition to ultrasound for $5 \mathrm{~min}$. The results show that the particles are easily dispersible and their size depends on the process parameters. The particle size decreases with increasing temperature and increasing flow rate, in addition the particle size distribution becomes smaller (Table 2). 
Figure 3. X-ray powder pattern of the obtained particles. The results show that pure zinc oxide was obtained.

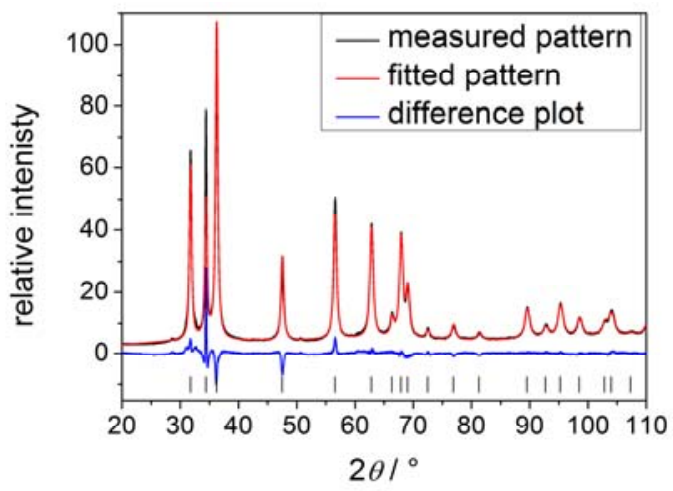

Table 1. Crystallite size in dependence on the process parameters.

\begin{tabular}{cc}
\hline Process parameters & Crystallite size \\
\hline $200 \mathrm{~mL} / \mathrm{min} / 25^{\circ} \mathrm{C}$ & $22.2 \pm 0.5$ \\
$200 \mathrm{~mL} / \mathrm{min} / 50{ }^{\circ} \mathrm{C}$ & $20.4 \pm 0.7$ \\
$200 \mathrm{~mL} / \mathrm{min} / 75^{\circ} \mathrm{C}$ & $16.3 \pm 0.3$ \\
$250 \mathrm{~mL} / \mathrm{min} / 25^{\circ} \mathrm{C}$ & $22.7 \pm 0.5$ \\
$250 \mathrm{~mL} / \mathrm{min} / 50^{\circ} \mathrm{C}$ & $21.3 \pm 0.4$ \\
$250 \mathrm{~mL} / \mathrm{min} / 75^{\circ} \mathrm{C}$ & $16.9 \pm 0.3$ \\
\hline
\end{tabular}

Figure 4. Particle sizes of the obtained zinc oxide particles determined by dynamic light scattering.
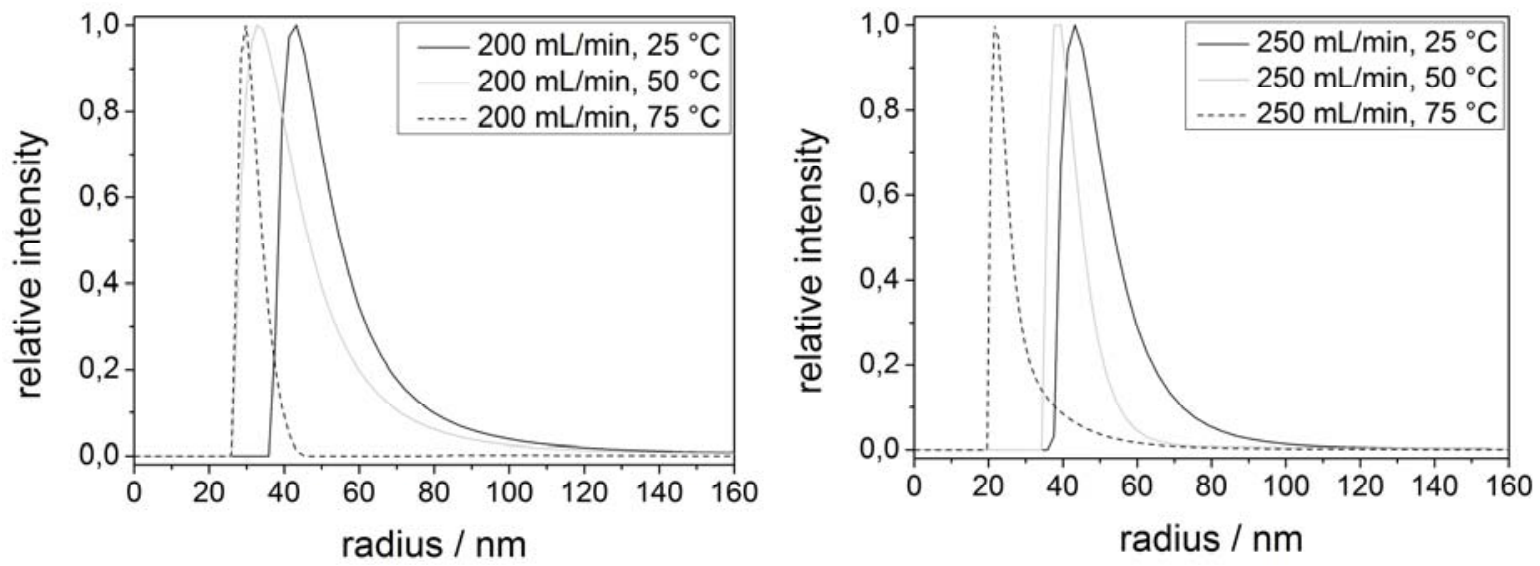

Table 2. Particle size determined using dynamic light scattering.

\begin{tabular}{cc}
\hline Process parameters & Radius/nm \\
\hline $200 \mathrm{~mL} / \mathrm{min} / 25^{\circ} \mathrm{C}$ & $51 \pm 7$ \\
$200 \mathrm{~mL} / \mathrm{min} / 50{ }^{\circ} \mathrm{C}$ & $41 \pm 8$ \\
$200 \mathrm{~mL} / \mathrm{min} / 75^{\circ} \mathrm{C}$ & $27 \pm 3$ \\
$250 \mathrm{~mL} / \mathrm{min} / 25^{\circ} \mathrm{C}$ & $43 \pm 6$ \\
$250 \mathrm{~mL} / \mathrm{min} / 50^{\circ} \mathrm{C}$ & $36 \pm 4$ \\
$250 \mathrm{~mL} / \mathrm{min} / 75^{\circ} \mathrm{C}$ & $22 \pm 2$ \\
\hline
\end{tabular}


The particle morphology was investigated by means of scanning electron microscopy (Figures 5 and 6 ). The images confirm that the particles are in the nanometer size range. However, SEM analysis does not show the pronounced differences in the particles sizes that were observed in the DLS measurements for the parameter variations. Generally, it can be observed in SEM that the particles are all sphere-shaped and the size distribution becomes more uniform with increasing temperature.

Figure 5. SEM images of zinc oxide synthesized with a flow rate of $200 \mathrm{~mL} / \mathrm{min}$ at $25{ }^{\circ} \mathrm{C}$ (left) and at $75^{\circ} \mathrm{C}$ (right).
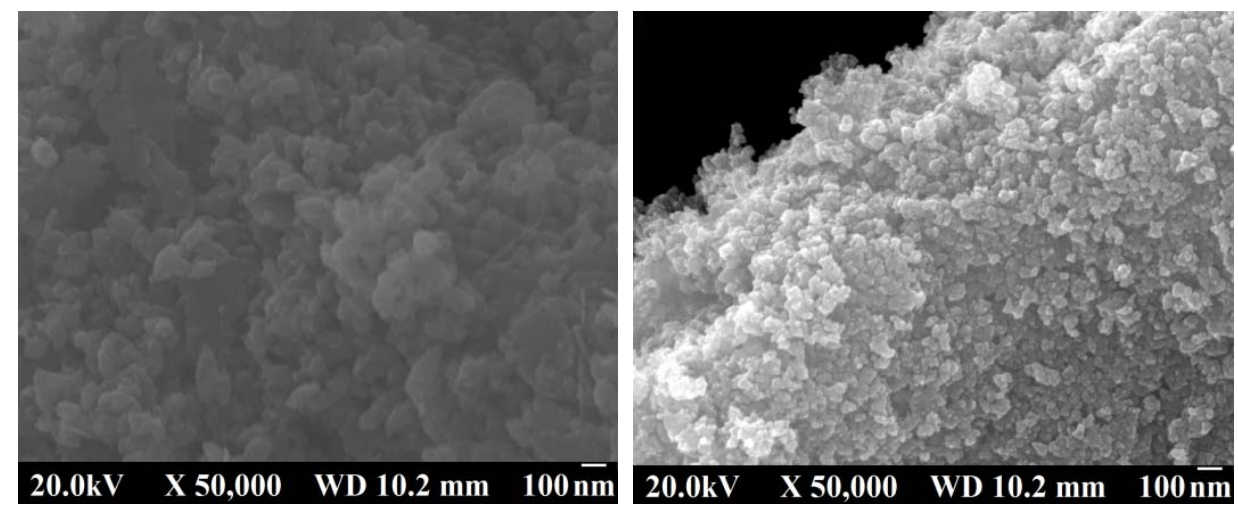

Figure 6. SEM images of zinc oxide synthesized at $50{ }^{\circ} \mathrm{C}$ with a flow rate of $200 \mathrm{~mL} / \mathrm{min}$ (left) and with a flow rate of $250 \mathrm{~mL} / \mathrm{min}$ (right).
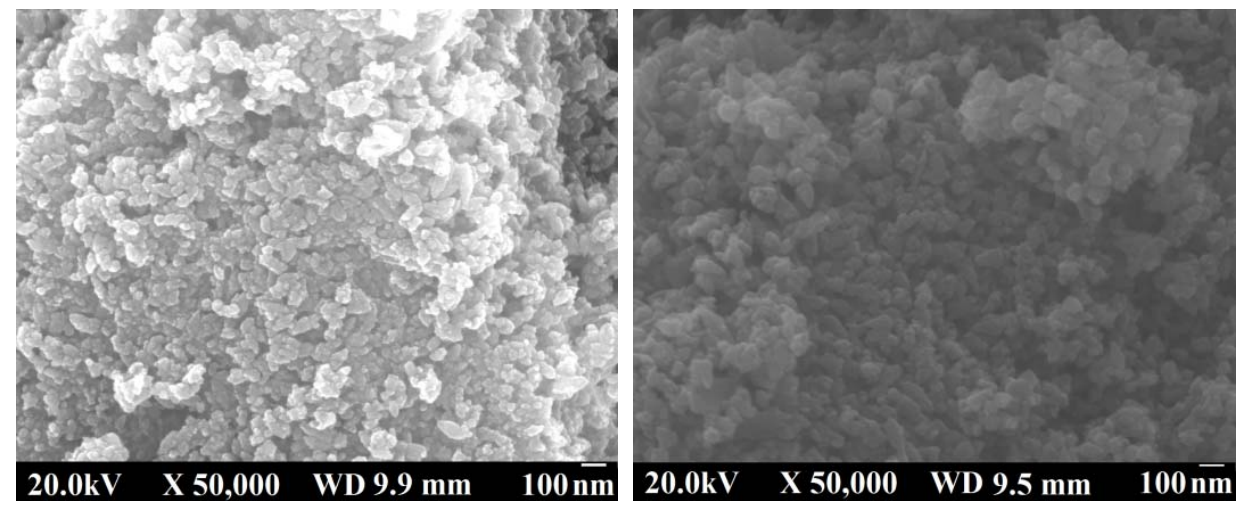

\subsection{Magnetite}

Systematic studies with respect to the synthesis of magnetite nanoparticles using a microjet reactor were performed with an aqueous solution of ferric and ferrous chloride as solution A and an ammonia solution B (Equation 2).

$$
\mathrm{FeCl}_{2}+2 \mathrm{FeCl}_{3}+8 \mathrm{NH}_{4} \mathrm{OH} \rightarrow \mathrm{Fe}_{3} \mathrm{O}_{4}+8 \mathrm{NH}_{4} \mathrm{Cl}+4 \mathrm{H}_{2} \mathrm{O}
$$

Ferrous chloride must be applied in excess because the synthesis was performed under air. Consequently, the $\mathrm{Fe}^{2+}$ ions tend to oxidize and form $\mathrm{Fe}^{3+}$ ions [27]. Magnetite nanoparticles were already obtained applying conventional synthetic routes using the same starting materials [28].

FT-IR analysis of the particles that were obtained in the microjet reactor does not show specific bands for the products with exception of the $\mathrm{Fe}-\mathrm{O}$ band around $500 \mathrm{~cm}^{-1}$. 
Thermo gravimetric analysis (Figure 7) was performed to determine if the samples contain any adsorbed species like water. The particles show a mass loss between 4 and 7\%, which can be explained by adsorbed water or the production of water by condensation of free hydroxyl groups.

Figure 7. Thermo gravimetric analysis of the final products. The samples show a mass loss of between 4 and $7 \%$.

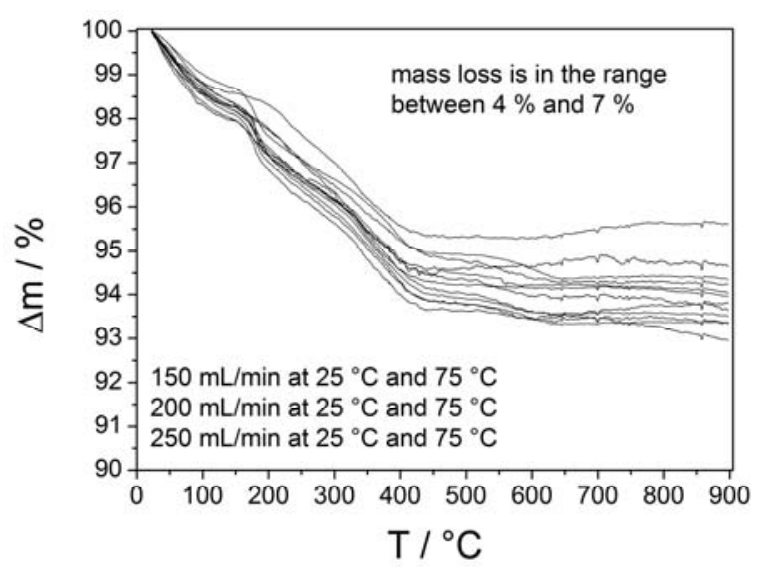

The phase composition and crystallite size of the obtained particles were determined by X-ray powder diffraction (Figure 8). The results show that magnetite with crystallite sizes around $10 \mathrm{~nm}$ were obtained in the microjet reactor. There are a few very weak reflections which cannot be correlated to magnetite. Consequently, there is a small fraction of an impurity phase. The reflection at approximately $2 \theta=32^{\circ}$ suggest this phase to be maghemite.

Figure 8. XRD pattern of the obtained particles. The results show that magnetite was obtained.

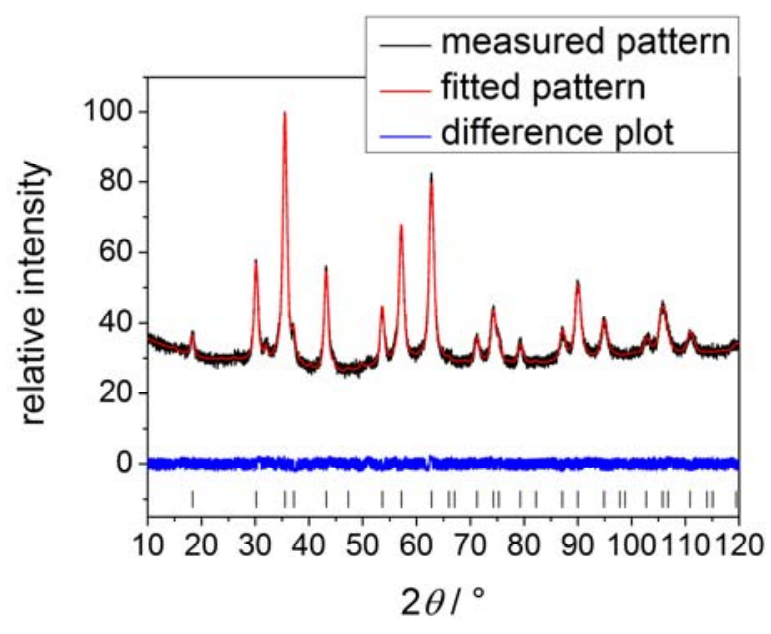

The particle size of the attained material was determined by using dynamic light scattering (Figure 9). The results reveal that particles between $46 \mathrm{~nm}$ and $112 \mathrm{~nm}$ were obtained. Just as in case of the $\mathrm{ZnO}$ particles the particle sizes including the size distribution decrease with increasing process temperature and flow rate (Table 3).

Previous studies applying rapid mixing techniques showed much smaller nanoparticle sizes around $7 \mathrm{~nm}$ [4]. The difference between the technique presented here and previous studies is the altered time 
for growth of the particles, which depends in our setup on the length of the tubing between microjetreactor and collecting vessel. We are currently investigating these parameters in an additional study.

Figure 9. Particle size of the synthesized magnetite determined by dynamic light scattering.
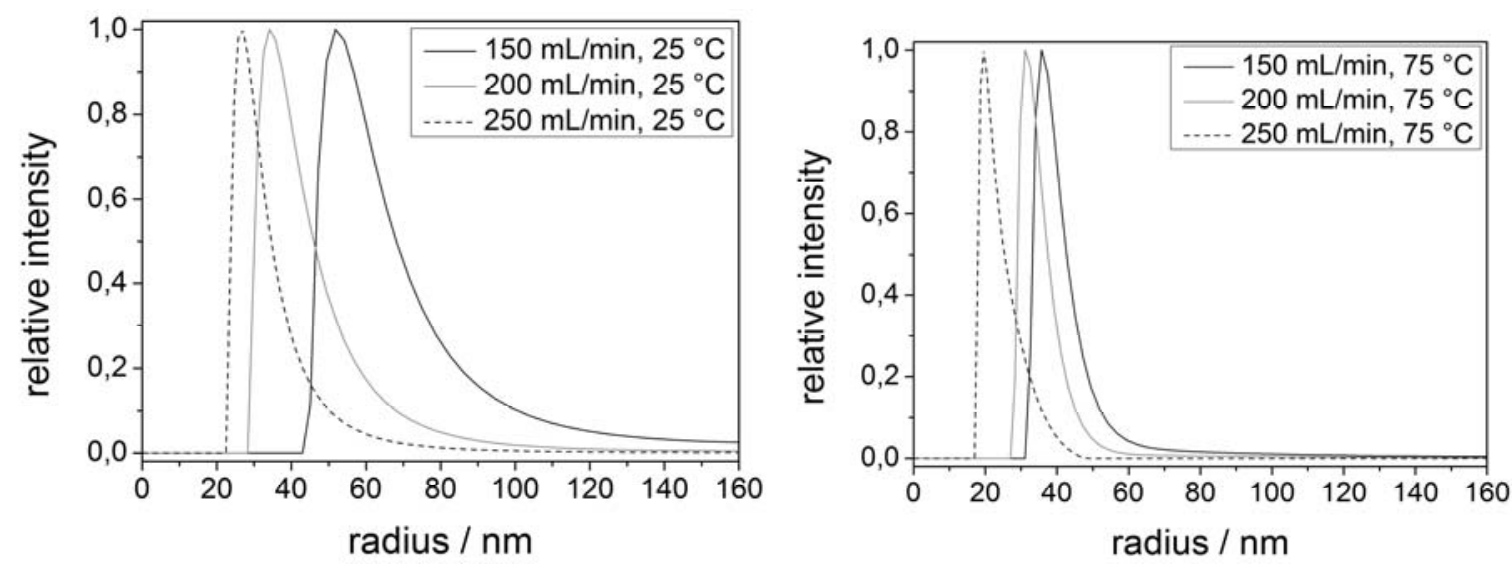

Table 3. Particle size determined using dynamic light scattering.

\begin{tabular}{cc}
\hline Process parameters & Radius $/ \mathbf{n m}$ \\
\hline $150 \mathrm{~mL} / \mathrm{min} / 25^{\circ} \mathrm{C}$ & $66 \pm 9$ \\
$200 \mathrm{~mL} / \mathrm{min} / 25^{\circ} \mathrm{C}$ & $42 \pm 7$ \\
$250 \mathrm{~mL} / \mathrm{min} / 25^{\circ} \mathrm{C}$ & $32 \pm 5$ \\
$150 \mathrm{~mL} / \mathrm{min} / 75^{\circ} \mathrm{C}$ & $41 \pm 4$ \\
$200 \mathrm{~mL} / \mathrm{min} / 75^{\circ} \mathrm{C}$ & $35 \pm 4$ \\
$250 \mathrm{~mL} / \mathrm{min} / 75^{\circ} \mathrm{C}$ & $23 \pm 3$ \\
\hline
\end{tabular}

SEM was applied to determine the morphology of the obtained magnetite particles (Figure 10). The results show that the particles are sphere-shaped and become smaller with increasing flow rate and temperature.

Figure 10. SEM images of the obtained magnetite particles synthesized at $25{ }^{\circ} \mathrm{C}$ with a flow rate of $150 \mathrm{~mL} / \mathrm{min}$ (left) and at $75^{\circ} \mathrm{C}$ with a flow rate of $250 \mathrm{~mL} / \mathrm{min}$ (right).
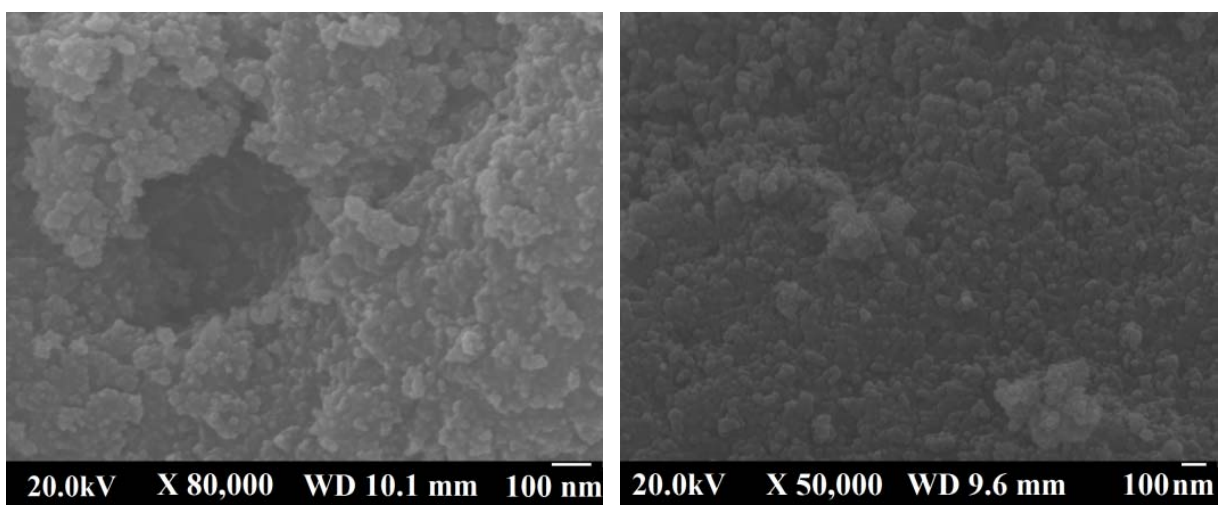


\subsection{Calcium Hydrogen Phosphate/Brushite}

As a third system the synthesis of calcium hydrogen phosphate particles using the mircojet-reactor was investigated. An aqueous solution of calcium nitrate (solution A) and di-ammonium hydrogen phosphate (solution B) were mixed in the microjet reactor (Equation 3). The $\mathrm{pH}$ of both solutions was adjusted to 5 in order to obtain the calcium hydrogen phosphate in the brushite phase.

$$
\mathrm{Ca}\left(\mathrm{NO}_{3}\right)_{2} \cdot 4 \mathrm{H}_{2} \mathrm{O}+\mathrm{HPO}_{4}\left(\mathrm{NH}_{4}\right)_{2} \rightarrow \mathrm{CaHPO}_{4} \cdot 2 \mathrm{H}_{2} \mathrm{O}+2 \mathrm{NH}_{4} \mathrm{NO}_{3}+2 \mathrm{H}_{2} \mathrm{O} \text {. }
$$

Using the same starting materials, but applying a conventional batch reactor synthesis route, plate-like brushite particles in the micrometer range were obtained [29]. Employing the microjet reactor for this reaction it turned out that the precipitation reaction does not proceed at $25{ }^{\circ} \mathrm{C}$. The material obtained using $75{ }^{\circ} \mathrm{C}$ as process temperature was analyzed with respect to composition and morphology. FT-IR analyses (Figure 11) of the obtained materials show that the synthesis of calcium hydrogen phosphate was successful at $75{ }^{\circ} \mathrm{C}$. The spectra show absorption bands between $1200 \mathrm{~cm}^{-1}$ and $400 \mathrm{~cm}^{-1}$ which is the typical $\mathrm{P}-\mathrm{O}$ region and indicates $\mathrm{P}-\mathrm{O}$ vibrations as well as vibrations of a $\mathrm{HPO}_{4}$ group. In addition, absorption bands relating to water are visible. At $1650 \mathrm{~cm}^{-1}$ there is the typical absorption band for the $\mathrm{H}_{2} \mathrm{O}$ bending. Furthermore, between $3550 \mathrm{~cm}^{-1}$ and $3000 \mathrm{~cm}^{-1}$, the absorption bands relating to the $\mathrm{OH}$ stretching of water are visible. This agrees well with FT-IR data of calcium hydrogen phosphate reported in the literature [30,31].

Figure 11. FT-IR spectra of the obtained materials. Absorption bands in the P-O region are observable as well as absorption bands relating to water. For each condition two spectra were shown in order to illustrate the reproducibility.

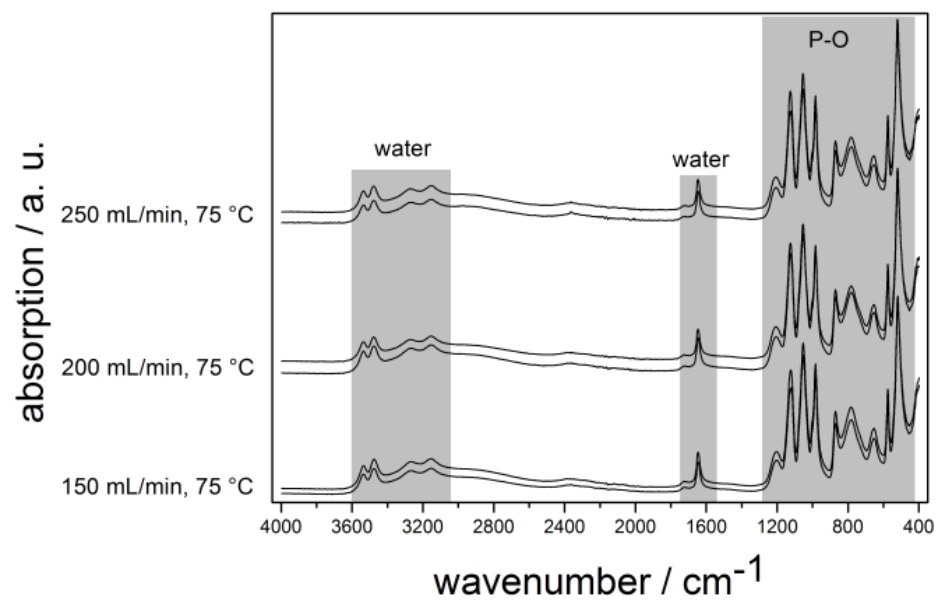

Thermo gravimetric analysis was performed to analyze the thermal decomposition of the obtained material (Figure 12). The results show that the decomposition takes place in two steps, which confirms that calcium hydrogen phosphate was obtained in the brushite phase. The first decomposition step proceeds between $100{ }^{\circ} \mathrm{C}$ and $350{ }^{\circ} \mathrm{C}$ degree and is relating to the loss of two molecules of crystal water. Consequently $\mathrm{CaHPO}_{4}$ is formed. The second decomposition step takes place between $350{ }^{\circ} \mathrm{C}$ and $600{ }^{\circ} \mathrm{C}$ and is relating to the loss of 0.5 water molecules per $\mathrm{Ca}^{2+}$ ion and the formation of $\mathrm{Ca}_{2} \mathrm{P}_{2} \mathrm{O}_{7}$. This is the typical pattern for decomposition of brushite. 
Figure 12. Thermal decomposition of the obtained material. The decomposition takes place in two steps, which is typical for the thermal decomposition of calcium hydrogen phosphate in the brushite phase.

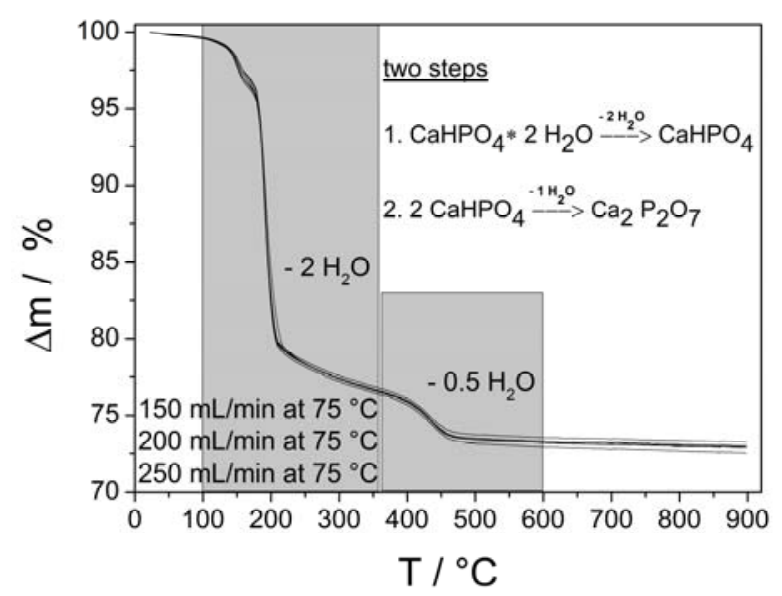

The results of the X-ray powder diffraction measurements (Figure 13) confirm that pure brushite was obtained. The particles show a high anisotropy in their crystallite sizes. An average crystallite size could be determined which is in the range of 200 to $300 \mathrm{~nm}$ depending on the reaction conditions.

Figure 13. X-ray powder pattern. Pure calcium hydrogen phosphate in the brushite phase was obtained.

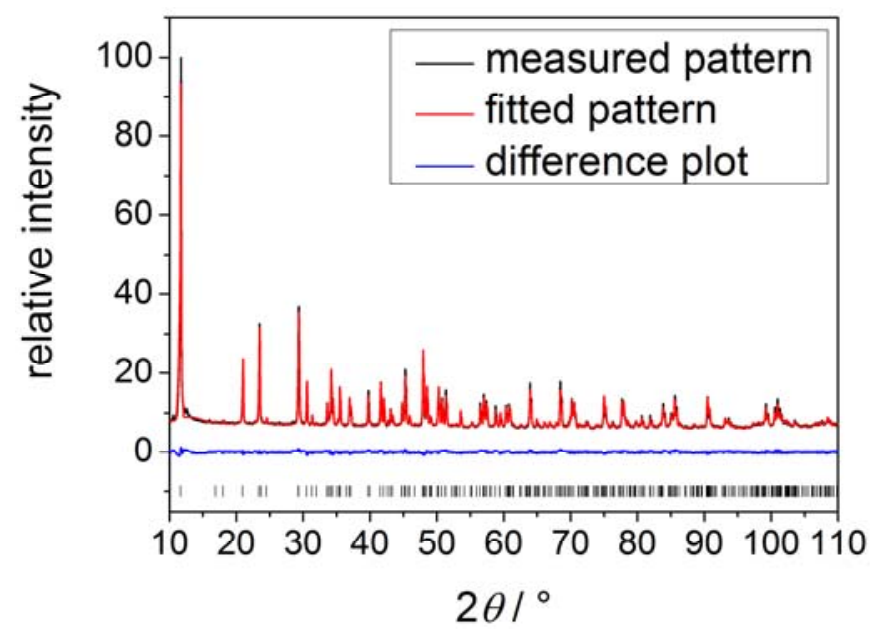

SEM was applied to analyze the morphology of the obtained material (Figure 14). The results show that the particles are shaped like small plates based on the layered structure of brushite. The layers grow faster in two directions so that plates are formed. The edge lengths of these plates were determined to be between $100 \mathrm{~nm}$ and $500 \mathrm{~nm}$. 
Figure 14. SEM image of the obtained material. Brushite synthesized at $75{ }^{\circ} \mathrm{C}$ with a flow rate of $250 \mathrm{~mL} / \mathrm{min}$.

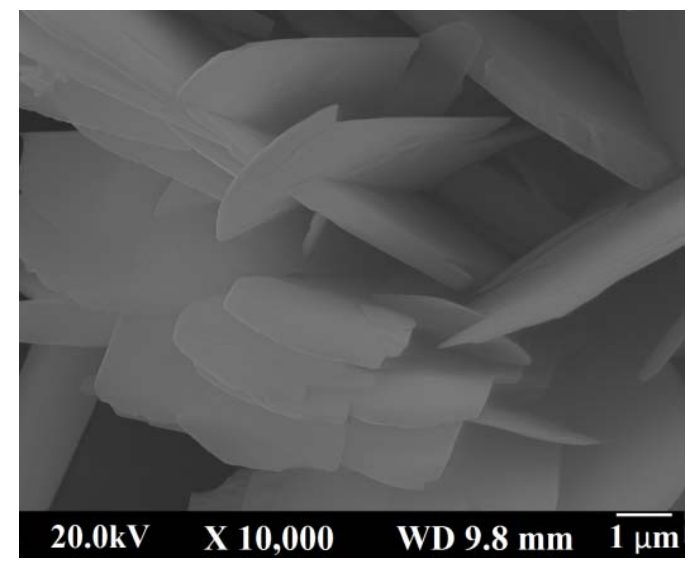

All three examples showed that the continuous production of nanoparticles, in case of $\mathrm{ZnO}$ and $\mathrm{Fe}_{3} \mathrm{O}_{4}$, or submicron sized plates in case of brushite is possible with the wet chemical microjet reaction technique. All samples showed that flow rates as well as temperatures have an important influence on the size and size-distribution of the particles. In the microjet environment the nuclei are formed and the particle growth most likely occurs in the tube between the reactor and the collecting vessel. We did not investigate the effect of this distance on the particle growth yet. This will be the focus of a further study.

\section{Experimental Section}

\subsection{Materials}

Zinc chloride, sodium hydroxide and ferric chloride were purchased from Grüssing GmbH (Filsum, Germany). Calcium nitrate and di-ammonium hydrogen phosphate were purchased from Fluka (Buchs, Switzerland). Ferrous chloride was purchased from Alfa Aesar (Karlsruhe, Germany). Ammonia was purchased from VWR (Fontenay-sous-Bois, France). All chemicals were used without further purification.

\subsection{Instruments and Characterization}

FT-IR measurements were performed under ambient air (40 scans at a resolution of $4 \mathrm{~cm}^{-1}$ ) in attenuated total reflectance (ATR) mode on a Bruker Vertex 70 spectrometer. X-ray powder diffraction was carried out on two different diffractometers a Panalytical X'Pert and a Bruker D8 Advance-system, Bragg-Brentano geometry and $\mathrm{CuK} \alpha$ radiation was used in both cases. The quantitative analysis was carried out by the Rietveld-method using the program TOPAS [32] and crystallographic data for the different species (zinc oxide [33], magnetite [34] and brushite [35]). Thermogravimetric analysis (TGA) was carried out on a Netzsch Iris TG 209. The sample was placed in an alumina crucible which was then heated from room temperature to $900{ }^{\circ} \mathrm{C}$ under nitrogen atmosphere with a rate of $20 \mathrm{~K} \mathrm{~min}^{-1}$.

Scanning electron microscopy (SEM) images were recorded on a JEOL SEM-7000 microscope. The SEM samples were prepared by placing some grains on a specimen stub with attached carbon adhesive foil followed by deposition of a gold layer. Dynamic light scattering (DLS) measurements were carried out on an ALV/CGS-3 compact goniometer system with an ALV/LSE-5003 multiple $\tau$ 
correlator at a wavelength of $632.8 \mathrm{~nm}$ (He-Ne Laser) and at a $90^{\circ}$ goniometer angle. The particle radius was then determined by the analysis of the correlation-function via the $\mathrm{g} 2(\mathrm{t})$ method followed by a logarithmic number-weighting (n.w.) of the distribution function.

\subsection{Synthesis}

The following experiments were performed in a microjet reactor construction. Two LaPrep P110 preparative HPLC pumps (VWR) are responsible for the transport of the solutions containing the starting materials as dissolved substances. The reaction takes place in a microjet reactor (Synthesechemie, Heusweiler, Germany and MJR PharmJet, Homburg, Germany) with a cone diameter of 300 micrometers. The precipitate was directly removed from the reactor by the use of a nitrogen gas flow. The length of the tube between the microjet reactor and the collecting vessel was $150 \mathrm{~cm}$. Zinc oxide was synthesized using a $1 \mathrm{M}$ aqueous zinc chloride and a $2 \mathrm{M}$ aqueous sodium hydroxide solution as starting materials. Magnetite was obtained using a $0.4 \mathrm{M}$ aqueous ammonia solution and an aqueous solution containing $0.0625 \mathrm{M}$ ferric and ferrous chloride respectively. Brushite was synthesized by using $0.2 \mathrm{M}$ aqueous solution of calcium nitrate and a $0.1 \mathrm{M}$ aqueous solution of di-ammonium hydrogen phosphate, the $\mathrm{pH}$ of both solutions was adjusted to 5 using acetic acid or ammonia. The synthesis of each species was performed using different process parameters. The temperature was varied between $25^{\circ} \mathrm{C}$ and $75^{\circ} \mathrm{C}$, the flow rate was varied between $150 \mathrm{~mL} / \mathrm{min}$ and $250 \mathrm{~mL} / \mathrm{min}$.

\section{Conclusions}

The microjet-reactor technique is a promising method for the continuous synthesis of inorganic nanoparticles. Systematic studies on the effect of the process parameters, such as flow rate and process temperature, show that the particle size is controllable by means of these parameters. Our aim was the continuous synthesis of inorganic nanoparticles with controllable particle size. In our work we successfully demonstrated that it is possible to obtain pure zinc oxide nanoparticles using the microjet-reactor system. The prepared particles are uniformly shaped with a particle size of between $44 \mathrm{~nm}$ and $102 \mathrm{~nm}$ depending on the reaction conditions. The same could be shown for the synthesis of magnetite nanoparticles that were obtained with particle sizes between $46 \mathrm{~nm}$ and $132 \mathrm{~nm}$. In both cases, the size distributions were quite small and decreased with increasing reaction temperature. Furthermore, we demonstrated the synthesis of calcium hydrogen phosphate (brushite) by using the microjet-reactor. In this case brushite as a layered structure formed small plates.

\section{Conflicts of Interest}

The authors declare no conflict of interest. 


\section{References}

1. Kango, S.; Kalia, S.; Celli, A.; Njuguna, J.; Habibi, Y.; Kumar, R. Surface modification of inorganic nanoparticles for development of organic-inorganic nanocomposites - A review. Prog. Polym. Sci. 2013, 38, 1232-1261.

2. Castro, F.; Kuhn, S.; Jensen, K.; Ferreira, A.; Rocha, F.; Vicente, A.; Teixeira, J.A. Process intensification and optimization for hydroxyapatite nanoparticles production. Chem. Eng. Sci. 2013, 100, 352-359.

3. Ying, Y.; Chen, G.; Zhao, Y.; Li, S.; Yuan, Q. A high throughput methodology for continuous preparation of monodispersed nanocrystals in microfluidic reactors. Chem. Eng. J. 2008, 135, 209-215.

4. Ström, V.; Olsson, R.T.; Rao, K.V. Real-time monitoring of the evolution of the magnetism during precipitation of superparamagnetic nanoparticles for bioscience application. J. Mater. Chem. 2010, 20, 4168-4175.

5. Van den Rul, H.; Mondelaers, D.; van Bael, M.K.; Mullens, J. Water-based wet chemical synthesis of (doped) ZnO nanostructures. J. Sol-Gel Sci. Tech. 2006, 39, 41-47.

6. Jones, A.; Rigopoulos, S.; Zauner, R. Crystallisation and precipitation engineering. Comput. Chem. Eng. 2005, 29, 1159-1166.

7. Chen, J.; Zheng, C.; Chen, G. Interaction of macro- and micromixing on particle size distribution in reactive precipitation. Chem. Eng. Sci. 1996, 51, 1957-1966.

8. Mersmann, A. Crystallization and precipitation. Chem. Eng. Process. 1999, 38, 345-353.

9. Luo, G.; Du, L.; Wang, Y.; Lu, Y.; Xu, J. Controllable preparation of particles with microfluidics. Particuology 2011, 9, 545-558.

10. Chen, G.; Luo, G.; Yang, X.; Sun, Y.; Wang, J. Anatase-TiO $\mathrm{T}_{2}$ nano-particle preparation with a micro-mixing technique and its photocatalytic performance. Mater. Sci. Eng. A 2004, 380, $320-325$.

11. Wagner, J.; Kirner, T.; Mayer, G.; Albert, J.; Köhler, J.M. Generation of metal nanoparticles in a microchannel reactor. Chem. Eng. J. 2004, 101, 251-260.

12. Zinoveva, S.; De Silva, R.; Louis, R.D.; Datta, P.; Kumar, C.S.S.R.; Goettert, J.; Hormes, J. The wet chemical synthesis of Co nanoparticles in a microreactor system: A time-resolved investigation by X-ray absorption spectroscopy. Nucl. Instrum. Methods Phys. Res. Sect. A 2007, 582, 239-241.

13. Du, L.; Wang, Y.J.; Lu, Y.C.; Luo, G.S. Preparation of highly purified $\beta$-tricalcium phosphate ceramics with a microdispersion process. Chem. Eng. J. 2013, 221, 55-61.

14. Schwarzer, H.C.; Schwertfirm, F.; Manhart, M.; Schmid, H.J.; Peukert, W. Predictive simulation of nanoparticle precipitation based on the population balance equation. Chem. Eng. Sci. 2006, 61, $167-181$.

15. Schwarzer, H.C.; Peukert, W. Experimental Investigation into the Influence of Mixing on Nanoparticles Precipitation. Chem. Eng. Technol. 2002, 25, 6, 657-661.

16. Lince, F.; Marchisio, D.L.; Barresi, A.A. A comparative study for nanoparticle production with passive mixers via solvent-displacement: Use of CFD models for optimization and design. Chem. Eng. Process. 2011, 50, 356-368. 
17. Lince, F.; Marchisio, D.L.; Barresi, A.A. Smart mixers and reactors for the production of pharmaceutical nanoparticles: Proof of concept. Chem. Eng. Res. Des. 2009, 87, 543-549.

18. Silva, V.M.T.M.; Quadros, P.A.; Laranjeira, P.E.M.S.C.; Dias, M.M.; Lopes, J.C.B. A novel Continuous Industrial Process for Producing Hydroxyapatite Nanoparticles. J. Dispersion Sci. Technol. 2008, 29, 542-547.

19. Penth, B. (K)ein Fall für die Fällung. Chem. Tech. 2004, 3, 18-20.

20. Penth, B. Kontinuierliche Produktion in Mikroreaktoren. German Patent DE 102006004350 A1, August 2006.

21. Rüfer, A.; Räuchle, K.; Krahl, F.; Reschetilowski, W. Kontinuierliche Darstellung von Bariumsulfat-Nanopartikeln im MicroJet-Reaktor. Chem. Ing. Tech. 2009, 81, 1949-1954.

22. Dittert, B.; Gavrilovic, A.; Schwarz, S.; Angerer, P.; Steiner, H.; Schöftner, R. Phase content controlled $\mathrm{TiO}_{2}$ nanoparticles using the MicroJetReactor technology. J. Eur. Ceram. Soc. 2011, $31,2475-2480$.

23. Djutisic, A.B.; Ng, A.M.C.; Chen, X.Y. ZnO nanostructures for optoelectronics: Material properties and device applications. Prog. Quantum Electron. 2010, 34, 191-259.

24. Sugawara, A.; Asaoka, K.; Ding, S.J. Calcium phosphate-based cements: Clinical needs and recent progress. J. Mater. Chem. B 2013, 1, 1081-1089.

25. Vékás, L.; Tombácz, E.; Turcu, R.; Morjan, I.; Avdeev, M.V.; Krasia-Christoforou, T.; Socoliuc, V. Synthesis of Magnetite Nanoparticles and Magnetic Fluids for Biomedical Applications. Nanomedicine-Basic and Clinical Applications in Diagnostics and Therapy. Else Kröner-Fresenius Symp. Basel Karger 2011, 2, 35-52.

26. Samanta, P.K.; Mishra, S. Wet chemical growth and optical property of ZnO nanodiscs. Optik 2013, 124, 2871-2873.

27. RuizMoreno, R.G.; Martínez, A.I.; Falcony, C.; Castro-Rodriguez, R.; Bartolo-Pérez, P.; Castro-Román, M. One pot synthesis of water compatible and monodisperse magnetite nanoparticles. Mater. Lett. 2013, 92, 181-183.

28. Fang, M.; Ström, V.; Olsson, R.T.; Belova, L.; Rao, K.V. Particle size and magnetic properties dependence on growth temperature for rapid mixed co-precipitated magnetite nanoparticles. Nanotechnology 2012, 23, 145601.

29. Arifuzzaman, S.M.; Rohani, S. Experimental study of brushite precipitation. J. Cryst. Growth 2004, 267, 624-634.

30. Petrov, I.; Soptrajanov, B.; Fuson, N.; Lawson, J.R. Infra-red investigation of dicalcium phosphates. Spectrochim. Acta 1967, 23A, 2637-2646.

31. Trpkovska, M.; Soptrajanov, B.; Malkov, P. FTIR reinvestigation of the spectra of synthetic brushite and its partially deuterated analogues. J. Mol. Struct. 1999, 480-481, 661-666.

32. Topas, V4.2; General profile and structure analysis software for powder diffraction data, User Manual; Bruker AXS: Karlsruhe, Germany, 2008.

33. Khan, A.A. X-ray determination of thermal expansion of zinc oxide. Acta Cryst. A 1968, 24, 403.

34. Okudera, H.; Kihara, K.; Matsumoto, T. Temperature Dependence of Structure Parameters in Natural Magnetite: Single Crystal X-ray Studies from 126 to 773 K. Acta Cryst. B 1996, 52, 450-457. 
35. Beevers, C.A. The Crystal Structure of Dicalcium Phosphate Dihydrate, $\mathrm{CaHPO}_{4} \cdot 2 \mathrm{H}_{2} \mathrm{O}$. Acta Cryst. 1958, 11, 273-277.

(C) 2014 by the authors; licensee MDPI, Basel, Switzerland. This article is an open access article distributed under the terms and conditions of the Creative Commons Attribution license (http://creativecommons.org/licenses/by/3.0/). 